\title{
Failure Analysis: Case Study Challenger SRB Field Joint
}

\author{
Kouroush Jenab and Saeid Moslehpour
}

\begin{abstract}
The Challenger Solid Rocket Boosters (SRB) Field Joint initial design was deemed as a direct cause of the shuttles catastrophic failure during lift off. The Field Joint SRB was a key component in containing dangerous gases produced in the SRB. After conducting research on the Challenger accident, a Fault Tree Analysis was developed to analyze the reliability of the SRB field joint configuration in relation to its goals. The reliability model will show how the field joint fell short in terms of operational reliability.
\end{abstract}

Index Terms —Failure analysis, SRB field joint, reliability.

\section{OVERVIEW OF FTA AND CHALLENGER SRB FIELD}

The purpose of the field-joint is to hold the four segments of the Solid Rocket Motor (SRM) together. It also functioned to seal hot gases of the burning propellant within the steel casing of the booster. If gases were to leak through the field-joint they could potentially burn through the external fuel tanks, causing a catastrophe.

According to [1], the lower edge of the top segment had a protruding tang that fit into a 3.5-inch clevis on the upper edge of the bottom segment. One hundred seventy-seven steel pins went through the tang and clevis joint to hold the SRM segments together. These segments maintained the structural integrity of the Solid Rocket Booster during launch. Upon ignition of the SRM, pressure within the booster peaked to 1000 lbs. per square inch. Burning propellant created hot gases that reach temperatures of 5800 degree Fahrenheit. Two O-rings on the inner flange of the clevis seal the field joint. The O-rings were about $1 / 4$ inch in section diameter and made from heat resistant Viton rubber. A small gap remained, therefore the O-rings were coated with Zinc Chromate to seal the joint and protect the O-rings from hot gases [1].

During the original field joint design several tests were conducted that revealed mechanical and thermal weaknesses. During the previous 23 flights, engineers performed inspections on the field joint O-rings. These inspections proved there was thermal damage to the O-rings post-flight. The damage was never to a point where secondary O-rings did not supplement the primary O-rings in preventing a catastrophe, leaking gas from the SRM.

However, during the Challenger launch temperatures differed from the previous 23 flights as mentioned in [2]. Temperatures from those flights ranged from 53 to 81 degrees Fahrenheit, versus 31 on the day of launch. The engineers failed to recognize and/or elevate the issue surrounding the

Manuscript received May 25, 2015; revised October 20, 2015

K. Jenab is with Faculty of the College of Aeronautics, Embry-Riddle Aeronautical University, FL, USA (e-mail: jenab@ieee.org).

S. Moslehpour is with the Department of Electrical and Computer Engineering, University of Hartford, CT, USA (e-mail: moslehpou@hartford.edu). effect of temperature in regards to field joint O-ring seal. As previously stated, the O-rings used in the original design were covered in putty that protected the rings from hot gases. This putty prevented the O-rings from rapidly reacting to quickly induced pressure in the field joint upon rocket motor ignition. During the event, the decreased temperature highlighted the thermal weakness of the O-ring assembly, ultimately leading to a mechanical destruction of the O-ring itself. Hot gases leaked from the field joint and eventually took its toll on the mission [2].

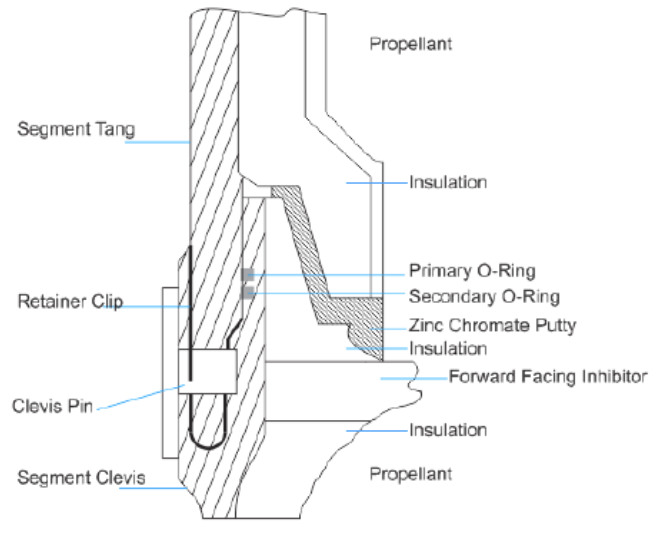

Fig. 1. Original vs. redesign.

Post-Challenger the SRM field-joint metal parts, internal case insulation and seals were redesigned. A detailed comparison of the redesign can be seen in Fig 1. A weather protection system was also added. Pressure actuation to the O-ring upstream face was determined essential for proper sealing. A tang captive feature was also introduced to provide positive metal-to-metal interference fit around the circumference of the tang and clevis ends of the mating SRM segments. In adding these changes, the field joint could handle twice the expected structural deflection and rate.

Although physical engineering changes were implemented to improve the reliability of the SRB field joint, there lacked analysis on the cause in effects of system failures. Using the FTA, potential causes of the SRB field joint failure can be analyzed and the effects can be determined.

\section{FTA LITERATURE ANALYISIS}

FTA is one of the most widely used reliability design techniques in the system development life cycle. It is applicable for risk assessment in system with a clearly identified single top event. Since FTA is event-oriented, differentiation between the levels of the events plays a vital role in creating the tree. By defining dependency relationship among the basic events, intermediate, and top events, the reliability measures can be estimated. The literature 
pertaining to FTA is concerned with sequential failure and common cause failures, using binary decision diagrams, Meta-heuristic i.e., knowledge-based system, expert system, neural networks, and Petri Nets, developing symbols, extending efficient algorithms to perform the FTA, and application of Fuzzy Sets. The knowledge-based system uses the knowledge encoded in some form such as rule-based systems decision tree. The construction of a fault tree knowledge base has been carried out by interviewing experts and painstakingly translating the experts' opinions into an appropriately structured set of rules (e.g., if-then). However, there are some sources of potential inconsistency that may result in conflicting conclusions in the knowledge base system. Alternatively, Petri Net approach is used for fault tree analysis. This approach like other Meta-heuristic approaches suffers from low accuracy in comparison with analytical approaches, painstakingly modeling of large-scale system, analysis difficulty of large-scale model, and desperately need computer-aided tools for practical applications. On the other hand, the use of fuzzy sets is criticized, because of the benchmarking of fuzzy variables in term of membership function.

In 1981, [3] developed a matrix FMEA technique to provide an organized and traceable analysis from the piece-part failure mode through all indenture levels to system level failure effects.

The following year, in 1982, [4] proposed the Matrix FMEA technique to perform a system interface analysis applicable in a telecommunication system. In the same year, [5] performed cost analysis versus reliability of the design that in customer point of view is configuration of the system. Takeda used fuzzy outranking relation in multi-criteria decision for failure mode and effects analysis [6].

In the following year, Kreuze presented the Built In Test System and its functions along with FMEA derived built in analysis [7].

In 1984, [8] addressed a logically extension of FMEA in the Built In Test System, which tested on a number of programs and showed a satisfied result and [9] provided a survey on FMEA and performed feasibility study on standardized automated FMEA technique.

Two years later, [10] introduced functional circuit analysis as a manual analysis technique that discussed design validation task and FMEA.

In 1988, [11] discussed the systems reliability assessment and efficient analysis for FMEA to improve the FMEA. [12] proposed fault simulation approach for FMEA or FTA as a complementary analysis technique.

In the following year, Raheja performed the software analysis to minimize the downtime as well as the vulnerable hardware of circuit system via FMEA [13] and Craig presented quality planning issues and its relation with reliability tools, such as FMEA [14].

Seven publications on the analysis in reliability design appeared in 1990. [15] developed a computer-based method of FMEA to analyze the electronic equipment and circuits with respect to the time consuming manual method. [16] introduced the structured qualification techniques such as FMEA to identify possible hazards in a chemical process. [17] developed FMEA method for improving manufacturing reliability in IC's package assembly since IC's are used in most circuit systems. [18] discussed circuit designing from the viewpoint of decision-making. [19] performed FMEA on the wind turbine circuit and as a result, many changes were made to the hardware. [20] extended the reliability approach by defining main function of each subsystem based on FMEA to find the possible failures and related consequence on safety. [21] addressed the symptom model based approach that correlates the failure symptom with ambiguity group using historical data.

In 1991, six papers appeared on FMEA. [22] urged using FMEA as a remarkable way to identify all catastrophic, critical and safety related failure possibilities. As well, [23] employed FMEA in design phase based on British standard 5760. [24] as a part of their project performed FMEA and diagnosis. However, as the traditional FMEA is slow and time inefficient, they designed a qualitative electrical circuit simulator that can model the structure and behavior of a system under analysis. [25] demonstrated the application of FMEA in chemical engineering. [26] addressed some of the practical problems associated with the application of FMEA and proposed a cost saving alternative method applicable to commercial software. The following year in 1992, eight articles presented various aspects of FMEA in the telecommunication area. [27] as a contractor in Kennedy Space Center performed FMEA to meet the shuttle "fail safe" programs requirements during design phase. [28] developed an expert system for FMEA. [29] implemented the safety standard related to solid state control for household electric ranges by using FMEA. [30] developed a tool that automates the reasoning portion of FMEA. It is built around a flexible casual reasoning module that has been adapted to the FMEA procedure. [31] presented a methodology combing the benefits of matrix FMEA and risk priority number technique. [32] determined reliability and maintainability of a power station including electrical and electronic circuits using FMEA. [33] presented a model to assess the availability of a controlled system by employing both FTA and FMEA. [34] extended FMEA simulation as an effective way to perform both FMEA and reliability analysis.

The year 1993 witnessed seven publications on FMEA. To assess the safety of embedded real time control system designed for using in automotive application, [35] adapted the traditional FMEA technique. [36] brought the feasibility of integrating FMEA and circuit analysis into a comprehensive reliability analysis technique. This study addressed the problem of how to best combine circuit analysis and FMEA to achieve benefit in the design phase. [37] designed a database system for storing FMEA data to improve the quality of analysis and make it more meaningful and visible. It also gave rise to the possibility of developing an integrated tool without database for related reliability analysis. [38] highlighted the benefits of the expert system technique to develop functional reasoning in a FMEA. [39] created an automated FMEA tool to make the analyzing process more time efficient. Later, a technique for evaluating the expected effectiveness of a design team configuration was presented by [40]. Ref. [41] presented a method for ranking failure modes based on the risk priority number.

The year 2002 witnessed five publications on FMEA. [42] 
proposed the fuzzy method based on linguistic variables, Grey theory, and Maximin method to determine an RPC for evaluating the risk level of the system. The approaches allow considerable weighing of severity factor associated with a cause of failure. Using min-max function and linguistic variables, [43] proposed that a system comprises the expert knowledge base rule and the failure factor interfaces to perform FMEA with uncertain and imprecise information. The knowledge maps into one or more if-then rule(s). However, conflict of rules and subsumption are the sources of potential inconsistency, which may result in conflicting conclusions in the knowledge base system.

The following year, in 2003, three publications appeared on FMEA. Using linguistic variables, [44] developed the fuzzy single-based expert rules to determine the RPC of the failure. The approach utilizes Grey theory to avoid the use of utility function. Because of time consuming, complexity of consistency check, and difficulty of maintenance of knowledge base approach, [45] proposed the fuzzy TOPSIS approach for FEA to avoid the definition of a knowledge base supported by several qualitative rules. Though TOPSIS method has some advantages, it suffers from sensitivity analysis because the criterion with the highest score has disproportionate influence in the failure ranking process. [46] developed fuzzy decision-making models with potential application in FMEA.

In 2004, to dilute conflict in a decision group, [47] and [48] presented a conflict resolution model to integrate multiple possibility distributions that can be used in Group-based Failure Effects Analysis (GFEA). [49] introduced the use of fuzzy random variables in the fuzzy Bayesian system reliability.

Ref. [50] developed a model for evaluating operational reliability of an aircraft environmental control system.

Ref. [51] developed a Master Logic Diagram (MLD) based on flow-graph to calculate time to failure data of a system.

There are multiple analytical methods used to analyze the risk of potential failures within a system. In the case of the Challenger, FTA will be used to develop a better approach to failure preventative practices. Amendment of the standard FTA method will capture specific events related to the Challenger operations, enhancing the quality assessment of events.

\section{FAult Tree ANAlysis OF THE Challenger FuILURE}

The FTA serves as a detailed diagram linking specified events to an overall fault based on system analysis through cause and effect. It covers both technical highlights the technical events that can transpire, leading to the top (failure) event, as illustrated in Fig. 2 below. In case of the Challenger, technical discrepancies within the SRB field joint were highlighted. Communication barriers underlying the management chain of the program were also a large contributing factor to its loss. In the operational world of the Challenger, engineering teams must communicate technicalities.

The FTA series of events and gates are developed based on the chart flow below. Specifics are derived from the operational environment that specified events are susceptive to. The Challenger Engineering team(s) communication of nertinent technical information is an event of interest in

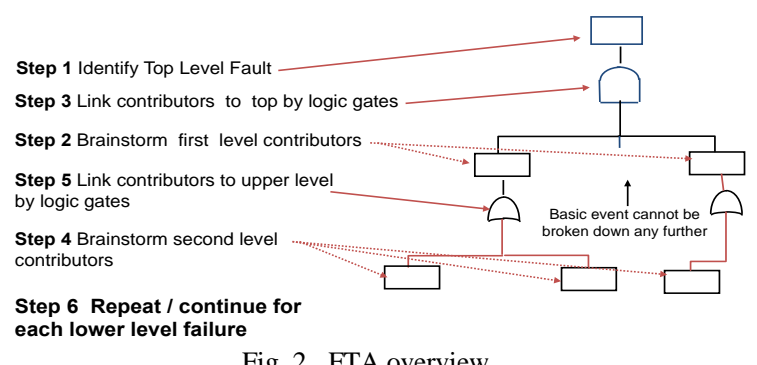

Fig. 2. FTA overview.

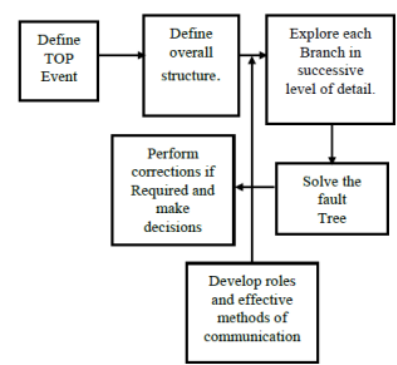

Fig. 3. FTA event analysis.

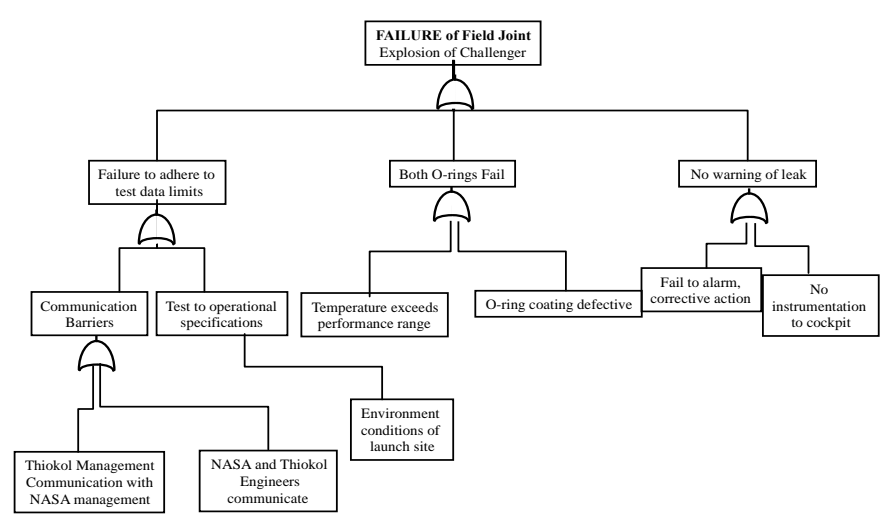

Fig. 4. SRB field joint FTA.

\section{ILLUSTRATIVE EXAMPLE}

The ability to produce, provide and collaborate data that affects the integrity of the mission is a key event in the operational process. The FTA below shows the effects of communication in relation to the Challenger. No other contributing failures were removed or degraded in the implementation of this event. The event serves as a linking contributor to the top event, failure.

\section{CONCLUSION}

The consideration and analysis of communication in the fault analysis process is highly important. It was implemented as a top-level contributor to failure based on the events taken from the Challenger explosion. Effective and open lines of communication are a key factor in maintaining a healthy operation and full spectrum on fault analysis. Relationships amongst

management-management, management-engineering, and engineering-engineering were all necessary in producing a successful launch of the 
Challenger. The study highlighted the defects of the current FTA in relation to catastrophic outcome of the Challenger launch. The amendment on the analysis of these communicative relationships in the FTA will improve the failure rate of future operations.

\section{REFERENCES}

[1] A. Sankar, C. S. Sankar, P. K. Raju, and V. Dasaka, "Implications and ramifications of engineering design of field joint for space shuttle: STS 51-L - A case study - instructor's guide," Journal of STEM Education, vol. 1 , no. 1 , pp. 37-59, 2000.

[2] Challenger Manufacturing and Assembly. [Online]. Available: http://science.ksc.nasa.gov/shuttle/technology/sts-newsref/sts_asm.ht $\mathrm{ml}$.

[3] S. A. Herrin, "Maintainability application using the matrix FMEA technique," IEEE Transactions on Reliability, pp. 212-217, 1981.

[4] S. A. Herrin, "System interface FMEA by matrix method," in Proc. the Annual Reliability and Maintainability Symposium, 1982, pp. 111-116.

[5] W. J. Lannes, "Cost-effectiveness analysis of substation arrangements," IEEE Transactions on Reliability, no. 4, pp. 212-217, 1982.

[6] E. Takeda, "Interactive identification of fuzzy outranking relation in a multicriteria decision problem," Fuzzy Information and Decision Processes- North-Holland-Amsterdam, pp. 301-307, 1982.

[7] F. J. Kreuze, "BIT analysis and design reliability," in Proc. the Annual Reliability and Maintainability Symposium, 1983, pp. 328-332.

[8] R. E. Collett and P. W. Bachant, "Integration of BIT Effectiveness with FMECA," in Proc. the Annual Reliability and Maintainability Symposium, 1984, pp. 300 -305.

[9] H. B. Dussault, "Automated FMEA status and future," in Proc. the Annual Reliability and Maintainability Symposium, 1984, pp. 1 -5.

[10] T. Jackson, "Integration of sneak circuit analysis with FMEA," in Proc. the Annual Reliability and Maintainability Symposium, 1986, pp. 408-412.

[11] S. Bednarz, "Efficient analysis for FMEA," in Proc. the Annual Reliability and Maintainability Symposium, 1988, pp. 416-421.

[12] K. Strandberg and H. Andersson, "Dependability testing of switching systems in the design phase," in Proc. the IEEE International Conference on Communications ICC '88 Digital Technology Spanning the Universe, 1988, vol. 2, no. 3, pp. $841-845$.

[13] D. Raheja, "Maintainability analysis for intelligent controls," IEEE Transactions on Reliability, pp. 385-393,1989.

[14] C. Craig, "Advanced quality planning issues," in Proc. the Thirty Fifth Meeting of the IEEE Holm Conference on Electrical Contacts,1989, pp. 101- 105.

[15] M. Lehtela, "Computer aided failure mode and effect analysis of electronic circuits," Microelectronics and Reliability, vol. 30, no. 4 , pp. 761-773, 1990.

[16] R. A. Freeman, "CCPS guidelines for chemical process: Qualitative risk analysis," Quality and Reliability Engineering International, vol. 9, no. 4, pp. 231-235, 1990.

[17] S. Prasad, "Improving manufacturing reliability in IC package assembly using FMEA technique," in Proc. the 19th International Electronic Manufacturing Technology Symposium Competitive Manufacturing for the Next Decade (IEEE/CHMT), 1990, pp. 356 -360 .

[18] H. J. W. Vliegen and H. H. V. Mal, "Rational decision making structuring of design meetings," IEEE Transactions on Engineering Management, vol. 37, no. 3, pp. 185 -190, 1990.

[19] W. E. Klein and V. R. Lali, "Model-OA wind turbine generator failure modes and effects analysis," in Proc. the Annual Reliability and Maintainability Symposium, 1990, pp. 337 -340.

[20] G. Cambi, R. Caporali, and S. Ciattaglia, "Reliability and safety analysis of magnet system for a NET type machine," in Proc. the 13th IEEE Symposium on Fusion Engineering, 1990, vol. 1, pp. 709 -712.

[21] A. Poon, W. J. Bertch, and J. B. Wood, "Next generation TPS architecture," in Proc. the IEEE Systems Readiness Technology Conference. 'Advancing Mission Accomplishment' Conference Record, 1990, pp. $51-61$.

[22] B. T. Mckinney, "FMEA, the right way," in Proc. the Annual Reliability and Maintainability Symposium, 1991, pp. 253-259.

[23] C. Kara-Zaitri, A. Z. Keller, I. Barody, and P. V. Fleming, "An improved FMEA Methodology," in Proc. the Annual Reliability and Maintainability Symposium, 1991, pp. 248 -252.
[24] A. R. T. Ormsby and M. H. Lee, "A qualitative circuit simulator," IEE Colloquium on Artificial Intelligence in Simulation, 1991.

[25] C. E. Citherel, "Forestalling," Chemical Engineering, vol. 98, no. 10 pp. 126-132, 1991

[26] R. D. Sexton, "An alternative method for preparing FMECA's," in Proc. the Annual Reliability and Maintainability Symposium, 1991, pp. 222 -225 .

[27] T. McCrea, "The shuttle processing contractors (SPC) reliability program at the Kennedy space center, the real world." in Proc. the Annual Reliability and Maintainability Symposium, 1992, pp. 376 -378 .

[28] D. J. Russomanno, R. D. Bonnell, and J. B. Bowles, "A blackboard model of an expert system for failure mode and effects analysis," in Proc. the Annual Reliability and Maintainability Symposium, 1992, pp. 483-490.

[29] M. Steinke, "Implementation of the standard for safety-related solid-state controls for household electric ranges," IEEE Transactions on Industry Applications, 1992, pp. 239 -250.

[30] D. Bell, L. Cox, S. Jackson, and P. Schaefer, "Using causal reasoning for automated failure modes and effects analysis (FMEA)," in Proc. the Annual Reliability and Maintainability Symposium, 1992, pp. 343 -353 .

[31] C. K. Zaitri, A. Z. Keller, and P. V. Fleming, "A smart failure mode and effect analysis package," in Proc. the Annual Reliability and Maintainability Symposium, 1992, pp. 414-421.

[32] C. Lishou, J. Lambert, B. Dakyo, and L. Protin, "An approach to the reliability of an insulated wind-solar power station design," in Proc. the 3rd Africon Conference, 1992, pp. 438-440.

[33] G. Caputo, C. Iannella, F. D. Luca, and G. Uguccioni, "Submarine pipeline automatic-repair system-an approach to the mission-availability assessment," in Proc. the Annual Reliability and Maintainability Symposium, 1992, pp. 126-130.

[34] D. L. Palumbo, "Using failure modes and effects simulation as a means of reliability analysis," in Proc. the 11th IEEE/AIAA Digital Avionics Systems Conference, 1992, pp. 102-107.

[35] P. L. Goddard, "Validating the safety of embedded real-time control systems using FMEA," in Proc. the Annual Reliability and Maintainability Symposium, 1993, pp. 227-230.

[36] D. S. Savakoor, J. B. Bowles, and R. D. Bonnell, "Combining sneak circuit analysis and failure modes and effects analysis," in Proc. the Annual Reliability and Maintainability Symposium, 1993, pp. 199 -205 .

[37] P. Kukkal, J. B. Bowles, and R. D. Bonnell, "Database design for failure modes and effects analysis," in Proc. the Annual Reliability and Maintainability Symposium, 1993, pp. 231-239.

[38] D. J. Russomanno, R. D. Bonnell, and J. B. Bowles, "Functional reasoning in a failure modes and effects analysis (FMEA) expert system," in Proc. Annual Reliability and Maintainability Symposium, 1993, pp. 339 -347.

[39] J. E. Hunt, C. J. Price, and M. H. Lee, "Automating the FMEA process," Intelligent Systems Engineering, vol. 2, no. 2, pp. 119-132, 1993.

[40] M. J. Safoutin and D. J. Thurston, "A communications-based technique for interdisciplinary design team management," IEEE Transactions on Engineering Management, vol. 40, no. 4, pp. 360-372, 1993.

[41] W. Gilchrist, "Modeling failure mode and effects analysis," International Journal of Quality and Reliability Management, vol. 10, no. 5, pp. 16-23, 1993.

[42] J. Puente, R. Pino, and P. Priore, "A decision support system for applying failure mode and effects analysis," International Journal of Quality and Reliability Management, vol. 19, no. 2, pp. 137-150, 2002.

[43] K. Xu, L. C. Tang, and M. Xie, "Fuzzy assessment of FMEA for engine systems," Reliability Engineering and System Safety, vol. 75, no. 1, pp. 17-29

[44] A. Pillary and J. Wang, "Modified failure mode and effects analysis using approximate reasoning," Reliability Engineering and System Safety, vol. 79, no. 1, pp. 69-85, 2003.

[45] M. Braglia, M. Frosolini, and R. Montanari, "Fuzzy TOPSIS approach for failure mode effects and criticality analysis," Quality and Reliability Engineering International, vol. 19, no. 5, pp. 425-443, 2003.

[46] J. T. Wang and Y. I. Lin, "A fuzzy multicriteria group decision making approach to select configuration items for software development," Fuzzy Set and Systems, vol. 134, no. 3, pp. 343-363, 2003.

[47] R. C. Wang and S J. Chuu, "Group decision-making using a fuzzy linguistic approach for evaluating the flexibility in a manufacturing 
system," European Journal of Operation Research, vol. 154, no. 3, pp. $563-572,2004$

[48] K. Jenab and B. S. Dhillon, "Group-based failure effects analysis (GFEA)," International Journal of Reliability, Quality and Safety Engineering (IJRQSE), vol. 12, no. 4, pp. 291-307, 2005.

[49] H. C. Wu, "Bayesian system reliability assessment under fuzzy environments," Reliability Engineering and System Safety, vol. 83, no. 3, pp. 277-286, 2004.

[50] K. Jenab and K. Rashidi, "Operational reliability assessment of an aircraft environmental control system," Reliability Engineering and System Safety, vol. 94, no. 2, pp. 456-462, 2009.

[51] K. Jenab, A. Sarfaraz, S. M. S. Hosseini, and B. S. Dhillon, "Dynamic MLD analysis with flow graphs," Reliability Engineering and System Safety, vol. 106, no. 1, pp. 80-85, 2012.

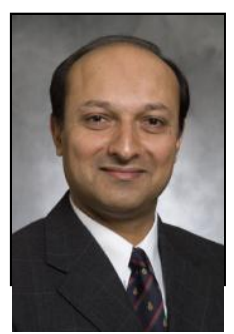

Kouroush Jenab is a senior member of IEEE. He received the B.Sc. degree from the IE Department at Isfahan University of Technology in 1989, the M.Sc. degree from the IE Department at Tehran Polytechnic in 1992, and the Ph.D. degree from the Department of Mechanical Engineering at the University of Ottawa in 2005 . He served as a senior engineer/manager in auto, and high-tech industries for 18 years. He joined the National Research Council Canada as a research officer where he participated in several international research projects. In 2006, he joined the Department of Mechanical and Industrial Engineering at Ryerson University, Toronto as assistant professor. Currently, Dr. Jenab is Faculty of the College of Aeronautics at Embry-Riddle Aeronautical University, FL, USA. He has published over 100 papers in international scientific journals based on his experiences in industries.

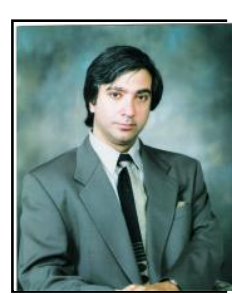

Saeid Moslehpour is full professor and departmen chair in the electrical and computer engineering department in the College of Engineering, Technology, and Architecture at the University of Hartford. He holds the Ph.D. in 1993 from Iowa State University and the bachelor of science in 1989 and the master of science in 1990 degrees from University of Central Missouri. His research interests include logic design, CPLDs, FPGAs, embedded electronic system testing and distance learning. 